\title{
TRANSTORNO DO DÉFICIT DE ATENÇÃO E HIPERATIVIDADE: IMPLICAÇÕES NO COTIDIANO ESCOLAR
}

\author{
ATTENTION DEFICIT AND HYPERACTIVITY DISORDER: IMPLICATIONS \\ IN SCHOOL EVERYDAY
}

\author{
Paulo Roberto Rodrigues Junior ${ }^{1}$
}

RESUMO: O presente artigo tem como objetivo elucidar o Transtorno do Déficit de Atenção e Hiperatividade (TDHA) aos profissionais de educação e áreas afins, incentivando o diagnóstico precoce, amenizando o baixo desempenho acadêmico e o índice de abandono escolar. Diferenciar os sintomas do TDAH pode ser fundamental para o indivíduo receber o tratamento adequado, não sendo confundido com problemas comportamentais. Problemas associados ao transtorno, como irritabilidade e ansiedade vão dificultar a leitura, escrita, comunicação e relacionamentos pessoais. Definições sobre as características do transtorno, percurso histórico, diagnóstico e tratamento são retratados neste trabalho. Para sua elaboração, teóricos foram usados como suporte, dentre eles Barkley (2008); Brown (2007); Mattos (2007); Vicari (2006), dentre outros que contribuíram substancialmente, além do conhecimento adquirido ao longo da carreira e formação. O método adotado foi a análise dos dados, obtidos com informações coletadas por meio de um questionário, com questões objetivas, relacionadas ao comportamento dos alunos, formação e preparação docente, conhecimentos e hipóteses acerca do TDAH e estratégias minimizadoras dos conflitos em sala. Diante desta análise foi possível observar que os professores têm conhecimento sobre a existência do transtorno e as características que mais descrevem essas crianças, entretanto ainda não conseguem diferenciá-lo de comportamentos excessivos e hábitos isolados. Por fim, comprovou-se a importância de promover a discussão sobre o modelo de gestão e metodologia, visto que o estudo revelou a tendência dos professores em correlacionar o comportamento inadequado do aluno a

1 Mestrando em Educação - Formação de Professores pela UNINI- Universidad Internacional Iberoamericana/México. Pós-graduado em Atendimento Educacional Especializado (2020). Pósgraduado em Atendimento Educacional Especializado - AEE (Grupo educacional Exatto 2020). Pósgraduado em Direito Aplicado à Educação (Faculdade Campos Elíseos 2018). Pós-graduado em Neuropsicopedagogia (Faculdade Campos Elíseos 2017). Pós-graduado em Psicomotricidade (Faculdade Campos Elíseos 2017). Especialização em Psicopedagogia (Faculdade Campos Elíseos 2020). Especialização em Dificuldades de Aprendizagem (2020). Especialização em Inovação Educação Conectada (Ministério da 2020). Especialização em Docência no Ensino Superior (2016). Especialização em LIBRAS (2014). Especialização em Alfabetização (2012). Graduado em Pedagogia pela Faculdade Anhanguera São José (2014). E-mail: paulo.rrodrigues49@gmail.com. 
causas familiares, emocionais e sociais, obliterando condutas que poderiam influenciar tais comportamentos.

Palavras-chave: Comportamento, Hiperatividade, Aprendizagem, Características.

ABSTRACT: This article aims to elucidate Attention Deficit Hyperactivity Disorder (TDHA) to education professionals and related areas, encouraging early diagnosis, mitigating low academic performance and the dropout rate. Differentiating the symptoms of ADHD can be essential for the individual to receive the appropriate treatment, not to be confused with behavioral problems. Problems associated with the disorder, such as irritability and anxiety, will hinder reading, writing, communication and personal relationships. Definitions about the characteristics of the disorder, history, diagnosis and treatment are portrayed in this work. For its elaboration, theorists were used as support, among them Barkley (2008); Brown (2007); Mattos (2007); Vicari (2006), among others who contributed substantially, in addition to the knowledge acquired throughout his career and training. The method adopted was data analysis, obtained with information collected through a questionnaire, with objective questions, related to student behavior, teacher training and preparation, knowledge and hypotheses about ADHD and strategies to minimize conflicts in the classroom. In view of this analysis, it was possible to observe that teachers are aware of the existence of the disorder and the characteristics that most describe these children, however, they still cannot differentiate it from excessive behaviors and isolated habits. Finally, the importance of promoting the discussion about the management model and methodology was proven, since the study revealed the tendency of teachers to correlate the student's inappropriate behavior to family, emotional and social causes, obliterating behaviors that could influence such behaviors.

Keywords: Behavior, Hyperactivity, Learning, Characteristics.

\section{INTRODUÇÃO}

$O$ interesse pelo tema é justificado pelo fato de muitos professores não conhecerem sobre o TDAH, suas características e com isso estereotipar a criança, rotulando com termos pejorativos como: "tem fogo", "no mundo da lua", "bagunceiro", "fora da casinha”, etc. Isso ocorre porque provavelmente tais docentes não conhecem a fundo sobre o transtorno, intensificando a problemática de que elas não foram diagnosticadas adequadamente durante a primeira infância, em período escolar, por profissionais da área de educação e saúde o que, por sua vez, não têm esclarecido a dimensão do transtorno. Assim, em geral, essas dificuldades são tratadas como indisciplina, desinteresse ou até mesmo como má educação. Hoje temos claro que o TDAH é definido como um transtorno neurobiológico que acomete crianças, adolescentes e adultos, independente de nível socioeconômico, raça ou religião. $\mathrm{O}$ Transtorno de Déficit de Atenção e Hiperatividade (TDAH) é um transtorno neuropsiquiátrico, reconhecido pela Organização Mundial de Saúde e registrado oficialmente pela Associação Americana de Psiquiatria no manual chamado de 
Diagnostic and Statistic Manual (DSM $\left.{ }^{2}\right)$. Sendo assim, Barkley (2008) caracteriza o TDAH como sendo:

um transtorno mental, encontrado em diversos países e que pode ser diferenciado, em seus principais sintomas, da ausência de deficiência e de outros transtornos psiquiátricos (BARKLEY, 2008, p.123).

A preocupação do estudo e conhecimento aprofundado sobre o tema deteve-se na concepção dos professores/educadores, pois ainda que este transtorno esteja sendo cada vez mais divulgado em tantos meios de comunicação, onde as ocorrências das informações são bem mais rápidas, ainda permanecem várias concepções desconexas sobre o tema. Ao contrário de serem encaminhados para profissionais da área de saúde para terem um diagnóstico mais adequado, às crianças em fase de desenvolvimento apresentam em suas características de comportamento sintomas semelhantes ao do TDAH como hiperatividade, desatenção e impulsividade, a pergunta que fica permeia é como os profissionais da educação analisam as crianças que apresentam tais sintomas? De acordo com o autor Paulo Mattos (2007), as crianças que apresentam o TDAH podem ser rotuladas como desinteressadas, mal-educadas, com problemas familiares, dificuldades de enxergar e ouvir, inclusive problemas de aprendizagem que dificultam seu desempenho acadêmico. Sabemos, no entanto, que tais crianças têm capacidade cognitiva preservada e apresentam rendimento escolar normal, desde que tratados adequadamente.

Entretanto, o despreparo e a falta de informação de alguns profissionais da área educacional contribuem para que essas características sejam acentuadas de forma excessiva em algumas crianças, por não serem associadas ao TDAH, e sim associadas a outros transtornos que dificultam a aprendizagem, tornando seu tempo acadêmico insatisfatório e enfadonho, desgastante e sujeito ao abandono. Frequentemente esses profissionais se sentem despreparados, no sentido de diminuir o impacto causado por esse transtorno.

\section{O TDAH e suas ramificações}

O processo de inclusão em escolas regulares, pois se excluem do processo de aprendizagem, achando-se incapazes de aprender qualquer conteúdo, seguir o ritmo dos demais, sendo tachadas de preguiçosas, lerdas, bagunceiras, desobedientes, sendo excluídas pelos colegas nas brincadeiras, trabalhos em grupo, etc. Faz-se necessário compreender quem são essas crianças, distingui-las das outras e identificar as características que as tornam tão especiais. A partir de 2008, a inclusão de crianças com $\mathrm{NEE}^{3}$ em escolas regulares passa a ser garantido por lei pela Política Nacional de Educação Especial na Perspectiva da Educação Inclusiva, contudo a mesma lei que

${ }^{2}$ O DSM está em sua $5^{\text {a }}$ edição.

${ }^{3}$ Necessidade Educacional Especial; de acordo com as Diretrizes Nacionais para Educação Especial na Educação Básica, MEC; SEESP, 200 . 
inclui, também exclui ao ponto que não prepara o ambiente escolar (físico e social) e nem a equipe escolar para o acolhimento dessas crianças em rede regular.

Com base em Duek e Noujorks, neste ponto afirmam que: "a inclusão faz alusão à capacidade de a escola rever sua estrutura organizacional como um todo, de modo a atender as necessidades de cada um dos seus alunos, engendrando estratégias em favor da sua formação integral (...)”. Então, a Educação Inclusiva, antes limítrofe à inserção física, após a Declaração de Salamanca (1994) e a Declaração da Educação para Todos (Brasil. UNICEF, I990) passa a partir da década de I990 deixando a encargo dos sistemas educacionais, realizar adaptações que atendam as demandas e reais necessidades desses alunos, promovendo a completa inclusão social.

Contudo, é necessário elucidar que crianças com o Transtorno de Déficit de Atenção e Hiperatividade (TDAH) sempre estiveram em escolas regulares, pois apesar da especificidade e real necessidade, não são vistas como especiais diante da lei que rege a educação inclusiva, o qual será detalhado no capítulo três.

Dentre outros pesquisadores sobre o assunto Thomas E. Brow (2007), Paulo Mattos (2007), Russell A. Barkley (2008), Maria Isabel Vicari (2006), assinalam o TDAH é um fator de risco para o baixo desempenho acadêmico e para os altos índices de abandono escolar, uma vez que essas crianças têm outros problemas associados que resultam em dificuldade de leitura e escrita, concentração, comunicação entre outros, que geram a sensação de incapacidade e inferioridade, causando a exclusão e até mesmo o abandono escolar.

Preocupado com tal situação que o autor Paulo Mattos (2007) descreve em relação ao desempenho acadêmico das crianças com TDAH que a intervenção pedagógica é de extrema importância, pois em determinados casos, pode-se evitar um transtorno maior em relação à escola e aos colegas de turma. Com isso esclarece que:

\footnotetext{
O problema é a escola participar do tratamento; muitas escolas não apenas desconhecem o TDAH como também não têm o desejo ou possibilidade de participar do tratamento, pelas mais variadas razões (MATTOS, 2007, p. 43).
}

Dessa maneira, a escola e mais precisamente os professores estão diretamente ligados ao diagnóstico do TDAH, identificando precocemente sintomas que encaminhe a criança a uma avaliação mais adequada e assertiva. E nesse caso, não apenas o professor, mas toda a equipe gestora e administrativa exercem funções importantes para a descoberta do diagnóstico e tratamento do transtorno, necessitando de informações acerca do TDAH, para que apoiem as crianças e os pais.

Uma das inquietações recorrentes, quando se trata de transtornos são a falta de recursos disponíveis, materiais e instalações são barreiras dos professores para a inserção dessas crianças na rotina escolar e desenvolvimento acadêmico, sendo assim de que maneira os professores trabalham com crianças que requerem mais atenção no processo de ensino aprendizagem?

\section{A escola regular, o TDAH e o processo de aprendizagem}


Outra inquietação está relacionada às escolas com caráter tradicional, onde o predomina o ensino sem interação, como nestas escolas as crianças são classificadas, aqueles que apresentam déficit de atenção/hiperatividade são classificados de que maneira? Em relação ao modelo tradicionalista Mattos (2007) destaca:

\footnotetext{
O sistema educacional tradicionalista penaliza quem tem TDAH... que sempre sigam todas as regras, que mantenham a atenção por horas seguidas e que sejam avaliados por provas monótonas e sem permissão para interrupções. (MATTOS, 2007,p.75)
}

Tal modelo tradicional de ensino raramente assimila as crianças com TDAH, uma vez que categoriza esse comportamento diverso dos padrões da escola ou sociedade. A criança com TDAH é considerada, por uma perspectiva comum, como inadequada, indisciplinada, produto de falha na educação familiar, e até mesmo como característica própria da personalidade do aluno. Por fim, como trabalhar o processo de inclusão desses alunos, visto que os portadores do TDAH apresentam problemas de interação, comportamento e relacionamento com o outro?

Diante dessas dificuldades de concentração, atenção, impulsividade e agitação as crianças com o transtorno estão sempre "extrapolando os limites" e a tendência é puni-los ou excluí-los, por parte dos pais, docentes e sociedade em geral. Ser portador de TDAH significa ter sempre sentimentos de inferioridade, baixa autoestima, desinteresse pelos estudos e ansiedade.

Segundo Paulo Mattos (2007), o portador de TDAH é descrito como sendo pessoa inquieta, que muda de interesse e plano o tempo todo, tendo dificuldades em levar as coisas até o fim, pois detesta coisas monótonas e repetitivas. Além disso, a impulsividade no seu dia a dia tende a ser problema na sua vida acadêmica (as queixas começam em geral, na escola), bem como na vida profissional, social e familiar. Por esses motivos é que acredito ser importante trazer esclarecimentos sobre o tema tanto para os profissionais da área de educação como para outros profissionais de áreas afins, bem como para os pais dessas crianças e comunidade em geral, pois com mais estudos e informação, melhor será a adaptação dessas crianças na sociedade.

É imprescindível esclarecer, que o TDAH é um transtorno de causas genéticas neurobiológicas que se manifestam na infância e não afeta a inteligência, entretanto as características do transtorno podem acarretar em problemas na aprendizagem e estar associados a outras comorbidades ${ }^{4}$ como: dislexia, Transtorno Desafiante de Oposição (TOD), Transtorno de Conduta (TC), Discalculia, Disortografia, etc. Dessa forma Brown (2007) descreve que o TDAH é tão complexo que inclui diferentes dificuldades, crônicas ou não, afetando as funções cognitivas e emocionais.

O termo atual usado para a denominação dos problemas apresentados por crianças quanto à atenção, impulsividade e hiperatividade é o Transtorno de Déficit de Atenção/Hiperatividade (TDAH), segundo Barkley (2008). Diversos rótulos grosseiros foram dados a essas crianças até que o termo atual chegasse a esse ponto. Seu percurso histórico foi longo e repleto de preconceitos e discriminação em relação

${ }^{4}$ Termo médico para o caso de uma pessoa ter mais de um transtorno. Ver Brown (2007), p. 138. 
às crianças que por não pararem um só segundo, eram rotuladas como desatentas e impulsivas no seu modo de serem, estabanados, agressivas, maus alunos, incontroláveis, bichos carpinteiros, preguiçosos, desatentos, desinteressados, barulhentos, mal-educados, etc.

Esse transtorno teve sua primeira descrição oficial em 1902, quando um médico pediatra inglês George Still apresentou dados clínicos de crianças que apresentavam agitação excessiva, eram desafiadoras, agressivas ou passionais, com hiperatividade e outras alterações comportamentais, que deveriam ser provocados por algum transtorno neurológico e não pelo meio educacional ou social. Still acreditava que essas crianças apresentavam grande "defeito no controle moral", que demonstravam ter pouca "volição inibitórias" e uma tendência a perpetrar atos desumanos, perversos, ilícitos e infames em sua conduta resultante de algum tipo de transtorno cerebral. Algum tempo depois, Still se depara com a afirmação de outro teórico e parte do princípio de que déficits de atenção Still acreditava que essas crianças apresentavam grande "defeito no controle moral", que demonstravam ter pouca "volição inibitória" e uma tendência a perpetrar atos desumanos, perverso, ilícitos e infames em sua conduta.

Posteriormente para explicar as deficiências no comportamento e aprendizagem, Barkley (2008) cita alguns teóricos onde utilizam a hipótese de lesões precoces, leves e absortas e com isso examinar possíveis melhorias na conduta, com mudanças no ambiente e medicamentos. Por esse motivo foi viável destacar a importância de ambientes planejados para crianças com necessidades educacionais especiais.

O interesse pelo tema foi motivado por uma crise de encefalite ${ }^{6}$ epidêmica entre 1917 e 1918, onde várias crianças sobreviventes à crise ficaram com sequelas comportamentais e cognitivas, permitindo assim um estudo aprofundado no TDAH. Os estudos sobre o transtorno continuam e, em 1980, o TDAH passa a ser um transtorno psiquiátrico infantil. Essa década ficou marcada pela publicação do transtorno no DSM-III, sendo criados subtipos do TDAH baseados na presença ou não da hiperatividade. Esse manual passado por novas atualizações, ainda descreve que para ser portadora do TDAH, a criança tem de ter no mínimo seis de uma lista de nove sintomas, segundo o Manual Diagnóstico - DSM-IV (1995).

A exemplificar as três subcategorias do TDAH: a) forma predominantemente desatenta, quando existem mais sintomas da desatenção. Este, segundo os estudos de Mattos (2008), é a forma mais comum na população em geral; b) forma predominantemente hiperativa / impulsiva, quando existem mais sintomas da hiperatividade e impulsividade, esta é a forma mais rara; e c) forma combinada, quando existem muitos sintomas das duas outras formas mencionadas acima. Esta é a forma mais comum nos consultórios e ambulatórios, provavelmente porque causa mais problemas para o próprio portador e para os demais, o que leva os pais a procurarem ajuda para o filho, segundo o autor Mattos (2008).

Em 1987, uma revisão no Manual Diagnóstico fez com que o nome de “Distúrbio de Déficit de Atenção” passasse para a condição de Transtorno de Déficit

\footnotetext{
${ }^{5}$ É o processo cognitivo pelo qual se decide participar de uma ação.

${ }^{6}$ Infecção aguda causada no encéfalo por vírus, bactérias, fungos, parasitas ou substâncias tóxicas.
} 
de Atenção / Hiperatividade (TDAH) o que desde então, o nome oficial continua agregando a desatenção aos problemas de comportamento hiperativos, classificado como um transtorno neurobiológico não afetando as funções cognitivas.

De acordo com o manual DSM-5 (Diagnostic and Statistical Manual, $5^{-\underline{a}}$ edição) o TDAH se caracteriza por um padrão persistente de desatenção e/ou hiperatividadeimpulsividade que interfere no funcionamento e no desenvolvimento sobre a desatenção, hiperatividade e impulsividade. Esses sintomas são listados no DSM-5 para tornar o diagnóstico mais padronizado e se caracteriza da seguinte forma: a) Sintomas da desatenção; seis ou mais sintomas persistindo por pelo menos seis meses e afetando a vida acadêmica e social do indivíduo; b) Sintomas de hiperatividade e impulsividade; seis ou mais sintomas persistindo por pelo menos seis meses e afetando a vida acadêmica e social do indivíduo.

De acordo com o DSM-5, os sintomas do TDAH manifestam-se em graus diferenciados e incoerentes em relação ao desenvolvimento infantil, com variação de intensidade, que podem causar problemas significativos nas habilidades acadêmicas e sociais.

\section{Metodologia aplicada à análise}

Para a pesquisa, foi utilizada a metodologia qualitativa descritiva, considerando a relação ativa entre a realidade e o sujeito entrevistado. Esse tipo de pesquisa proporcionou que os objetivos fossem alcançados na medida em que permitiu registrar, analisar e assimilar fatos ou ocorrências a partir das informações fornecidas pelos entrevistados em relação às suas ações. Sendo assim, tal metodologia permitiu traduzir e interpretar as opiniões e informações transmitidas pelos entrevistados, obtendo um melhor ordenamento e análise dos dados.

Segundo os autores Cervo, Bervian e Da Silva (2007), o modelo de pesquisa qualitativa descritiva permite: "conhecer as diversas situações e relações que ocorrem na vida social, política, econômica e demais aspectos do comportamento humano, tanto individualmente como em grupo e/ou de comunidades mais complexas." (p.6I). É nesse sentido que se relaciona os dados obtidos da pesquisa com as situações cotidianas e na troca de experiências.

Este padrão de pesquisa é aplicado principalmente por pesquisadores nas áreas de ciências humanas e sociais por abordarem dados e problemas a partir de seu desempenho e processo. Viabilizando os resultados da pesquisa, comparando os dados e fornecendo maiores subsídios para estudos futuros.

Os autores Cervo, Bervian e Da Silva (2007) ainda esclarecem que esse tipo de metodologia assume diversas formas, entre as quais se destacam: "Estudos Descritivos, Pesquisa de Opinião, Pesquisa de Motivação, Estudo de Caso e Pesquisa Documental." Nesse aspecto, o tipo da apresentação deste trabalho caracteriza-se por um Pesquisa Documental e de Opinião, por abordar a revisão de documentos oficiais do governo e trabalhar com pesquisa de opinião, e Estudo de Caso, pois ainda segundo a esses autores o estudo de caso é: "a pesquisa sobre determinado indivíduo, família, 
grupo ou comunidade que seja representativo de seu universo, para examinar aspectos variados de sua vida." (p.62).

Conquanto, foi escolhida como técnica de pesquisa a utilização de questionário devido ao tempo para aplicação e análise dos dados, que segundo Marconi e Lakatos (2002), proporciona: "respostas mais rápidas e precisas, maior liberdade nas respostas, em razão do anonimato e menos risco de distorção, pela influência do pesquisador", dentre as quais podemos aferir e comparar os resultados obtidos, analisando a partir da realidade dos profissionais que nos agraciaram com suas respostas.

Foi utilizada a aplicação de um questionário por meio do "google forms", uma ferramenta que permite a criação de formulários on-line disponíveis no google, viabilizando o tempo de resposta e a análise dos dados coletados. Essa técnica também favoreceu o tempo dedicado às leituras bibliográficas.

Os quesitos para compor a pesquisa foram selecionados de modo a atingirem as expectativas previstas nesse trabalho, respondendo aos bulícios e tendo por base os conhecimentos teóricos que foram acumulados ao longo dos anos.

O questionário foi aplicado aos professores da Rede Municipal de Ensino de São José dos Campos, na Escola X. Apenas oito professores dos anos iniciais responderam o formulário, isso já nos fornece material suficiente para análise e a veracidade do questionário, dos objetivos alcançados e das informações colhidas.

O TDAH tem influência na atenção/concentração, irritabilidade, humor, hiperatividade, entre outros fatores comportamentais, não apresentando déficits cognitivos. Caso venha a apresentar sinais de atraso cognitivo e ou dificuldades de aprendizagem, deve-se considerar a possibilidade de outras comorbidades que possam estar associadas ao transtorno, tais como dislexia, discalculia, disortografia, Transtorno do Espectro Autista, Transtorno Desafiante de Oposição, entre outros que podem ser diagnosticados por especialistas.

Um dos traços mais perceptíveis e marcantes no transtorno é a impulsividade, que geralmente é caracterizada pela dificuldade no controle dos impulsos, ou seja, o indivíduo não consegue controlar seus desejos, ocasionando assim, sofrimento ou angústia seja quer para si, ou para os outros de seu convívio. Não mede seus atos antes de agir. Colocar de lado o uso da linguagem interna, o parar e pensar antes de agir, não medindo as consequências. Esta mesma característica pode ser confundida com espontaneidade ou inclusive falta de educação, o que não é verdade, pois a linha entre "ser espontâneo", "mal-educado" e "impulsivo" é bastante distinta.

Outro aspecto é a conhecida popularmente agitação, mais comumente nos dias de hoje e divulgada como hiperatividade, que é a atividade que excede a idade e o meio onde está situado o indivíduo. A hiperatividade está associada a diversos fatores, como a frequência (com que constância ela acontece?), sua duração (quanto tempo dura esta hiperatividade?) E a intensidade (o quão intensa é a atividade?), deve ser ajustada a um contexto, determinada situação e um fim, não sendo classificada apenas como motora ou verbal, a hiperatividade perpassa os campos do cognitivo, desencadeando uma atividade cerebral maior, gerando assim a dificuldade de concentração do indivíduo.

Percebe-se tamanha atividade cerebral nas crianças com o transtorno, pois aparentam ter a famosa "pilha que nunca acaba" demonstrando grande movimentação, mesmo quando paradas (mexer os pés, sacudir as pernas). Quando sentadas por muito 
tempo demonstram grande inquietação e trocam de posição com frequência, pois não conseguem ficar sentadas ou quietas, tendem a tocar os objetos ao redor com regularidade, falam demais, cantarolam, assobiam ou fazem barulhos com a boca quando na verdade deveriam estar em silêncio e quietas. Sentem menos desejo de repousar ou dormir, sempre mordiscando um alimento, mordem tudo (lápis, borracha, mangas das camisas etc.).

Semelhante em conjunto com os dois traços acima, podemos destacar um terceiro que também afeta o indivíduo com TDAH, a falta de concentração. Como a atividade cerebral está em constante movimento devido à hiperatividade, como resultado temos a falta (ou pouca) concentração do indivíduo. A concentração demanda de um esforço cognitivo específico para ser realizada com eficiência, porém quando se trata de pessoa com TDAH, com a impulsividade nas ações e a hiperatividade em realizar afazeres, a concentração fica comprometida devido à movimentação cerebral intensa, gerando um desconforto ficar pensando em determinada atividade durante um período de tempo. Aí entramos com a frase "só tem cinco minutos de atenção", pois o tempo médio de esforço de uma criança com TDAH para as atividades escolares acaba sendo reduzido por excesso do trabalho cerebral em manter a concentração e fazer a atividade.

Nesse sentido percebemos a importância do professor no processo de aprendizagem das crianças com déficit de atenção e hiperatividade, pois identificando o quanto antes, quando algo não vai bem e, em parceria com especialistas, pais e familiares, desenvolverem atividades e estratégias que consigam minimizar este quadro e melhorar o desempenho escolar.

O Transtorno de Déficit de Atenção e Hiperatividade, quando diagnosticado em crianças, encontra-se intimamente ligado à existência do mesmo transtorno ou, alguns dos sintomas, no pai ou na mãe. Essa ocorrência do TDAH em parentes de crianças com esse diagnóstico é, no mínimo, levantada a hipótese de o transtorno ser geneticamente hereditário. As principais pesquisas sugerem que o TDAH é de natureza hereditária, sendo uma das citologias ${ }^{7}$ mais importantes para o transtorno. Mesmo o TDAH sendo de origem genética, não existe um único gene que o define, pois, o mesmo é chamado de poligênico já que são vários os genes que em conjunto dão origem ao transtorno. Barkley (2008) ressalta que pesquisas recentes acerca da hereditariedade e genética denotam uma forte base hereditária para o desenvolvimento TDAH (...)”.

\section{CONCLUSÃO}

Sabe-se que o ambiente não é um denominador do transtorno, porém a interação com o ambiente pode somar-se aos sintomas. Ao longo da gestação, fatores não genéticos podem estar envolvidos no aparecimento do transtorno, como: o consumo de álcool, o uso de drogas, desnutrição, fumo e problemas durante o parto. Entretanto, para que uma pessoa possa ser categorizada como portadora do TDAH é iminente que estejam presentes no mínimo seis dos sintomas listados pelo DSM - 5

\footnotetext{
${ }^{7}$ Estudo do desenvolvimento e das funções das células.
} 
dos nove sintomas de desatenção e/ou, no mínimo, seis da lista de nove sintomas de hiperatividade de acordo com o manual.

Estudos mostram que os portadores de TDAH sofrem alterações no lobo frontal do cérebro e suas conexões com o restante do órgão. Esta região é responsável pela inibição de comportamentos inadequados, capacidade de atenção, memória, autocontrole, planejamento e organização. A possível alteração nessa região cerebral é a regulação de substâncias químicas chamadas de neurotransmissores, a dopamina e noradrenalina que transmitem a informação entre as células nervosas.

O processo de aprendizagem não está limitado a um sistema de decoração de códigos e conteúdo, e sim a um desenrolar contínuo que opera sobre as informações assimiladas, processam os dados e organiza a memória, com certo grau de dificuldade, dando significado o qual será utilizado e aprimorado de acordo com as capacidades cognitivas. É imprescindível que a escola formalize sugestões propiciando a concentração e o desenvolvimento da criança com déficit de atenção, utilizando estratégias para aperfeiçoar $o$ aprendizado $e$ armazenar as informações significativamente.

Esse processo de inclusão pode parecer penoso, pois os colegas de classe não compreendem com tanta facilidade do que se trata, gerando desconforto, em sala e fazendo com que o portador de déficit de atenção e hiperatividade sofra um afastamento por parte dos colegas de sala, que o veem como intrometido, chato, atrapalha a aula, não espera a vez de falar e nem escuta, o que nesse sentido leva a criança a ser estigmatizada e excluída afastando-se do grupo e isolando-se. Quando criança, principalmente nas séries iniciais este problema deve ser prevenido, pois na adolescência é que irá refletir essa exclusão, quando o adolescente começa a se afastar das pessoas e abusar de bebidas alcoólicas, entrando em confusões.

Dos profissionais entrevistados, 40\% são pós-graduados, 30\% apenas com graduação e outros 30\% com superior incompleto, sendo que mais da metade atua nas séries iniciais de alfabetização e I0\% no ciclo II ( $6^{\circ}$ ao $9^{\circ}$ ano). Quanto à atuação com crianças com NEE, apenas $20 \%$ sentem-se preparado para desenvolver um trabalho seguro com as especificidades da criança, enquanto $80 \%$ não se sente confortável com a situação ou não sente preparo nenhum para atuar neste campo. Entretanto é unânime a visão de que a escola precisa capacitar seus profissionais e disponibilizar recursos para o atendimento especial, bem como a estrutura escolar deve ser adaptada para atender às demandas que chegam.

Crianças que apresentam tais características, desconhecendo que seu comportamento é inerente à sua personalidade leva a julgar que a criança é maleducada e merece ser castigada. Para o portador do transtorno é difícil a compreensão do motivo de ser excluído, gerando um sentimento negativo e fazendo com que este comportamento se transforme em algo pior, violento e às vezes, fora de controle, pois seu comportamento é involuntário, difícil de ser percebido por ele gerando um sentimento de tristeza, baixa autoestima, ânimo rebaixado, depressão, ansiedade, sintomas físicos, como dores de cabeça ou de barriga, dentre outros sintomas.

A formação continuada do professor nas séries iniciais é fundamental para a percepção de sinais que possam levar ao diagnóstico precoce dos transtornos relacionados ao indivíduo. Para isso a Política Nacional da Educação Especial na Perspectiva da Educação Inclusiva desta que: 
na perspectiva da educação inclusiva, a Resolução CNE/CP no I/2002, que estabelece as Diretrizes Curriculares Nacionais para a Formação de Professores da Educação Básica, define que as instituições de ensino superior devem prever, em sua organização curricular, formação docente voltada para a atenção à diversidade e que contemple conhecimentos sobre as especificidades dos alunos com necessidades educacionais especiais (MEC/SEESP, 2008).

A abordagem da educação inclusiva nas escolas regulares sugere preparar o professor para a necessidade real do educando, viabilizando a inclusão e conseguinte a necessidade de a reestruturação das escolas adequarem-se da melhor maneira à especificidade de cada criança, melhorando de forma educacional, revendo processos de aprendizagem, reconhecendo as necessidades educacionais e buscando a qualidade. Nesse sentido a Secretaria de Educação e a Secretaria de Educação Especial reconhecimento dessa complexa diversidade é que a criaram um material para nortear, paramentar solidificando o didático-pedagógico intitulado “Adaptações Curriculares”, que compõe o conjunto dos Parâmetros Curriculares Nacionais - PCN (1998), na tentativa de subsidiar os professores na sua tarefa de adaptações e integração desses alunos na escola regular de ensino e que propõe o seguinte:

\footnotetext{
a adequação curricular ora proposta procura subsidiar a prática docente propondo alterações a serem desencadeadas na definição dos objetivos, no tratamento e desenvolvimento dos conteúdos, no transcorrer de todo processo avaliativo, na temporalidade e na organização do trabalho didáticopedagógico no intuito de favorecer a aprendizagem do aluno (PCN, 1998, p. 13).
}

Sendo assim, Santos (2002), em seu artigo afirma: "a Educação Inclusiva se contrapõe à homogeneização padronizada de alunos, conforme critérios que não respeitam a diversidade humana", ou seja, quebra o dogma de que os alunos são iguais, os padrões são excluídos e formados novos modelos de educação, visando o aproveitamento de todos na escola.

Uma questão levantada no questionário relaciona os comportamentos das crianças, fazendo um levantamento do que o professor considera um comportamento e do que considera fora do aceitável. Nos principais tópicos selecionados estão a agitação como um comportamento fora do comum, a desatenção, impulsividade e o nervosismo também ganham terreno quando se trata de comportamento prejudicial em sala de aula. Podemos observar também, em grande número de respostas, que os docentes relacionam estes comportamentos aos distúrbios de aprendizagem ou dificuldades de compreensão e aos problemas neurobiológicos encontrados em distúrbios cognitivos, que impedem o desenvolvimento acadêmico da criança. Os entrevistados acreditam que diversos problemas de aprendizagem ou dos comportamentos listados por eles podem ser causados pela hereditariedade, meio sociocultural, dificuldades ou distúrbios de aprendizagem, pelo desinteresse na escola e/ou baixa autoestima. 
Os problemas emocionais e familiares também têm grande repercussão no desenvolvimento acadêmico da criança, gerando um desconforto na escola e criando problemas psicológicos que, se não tratados adequadamente, podem levar a criança a quadros de síndrome do pânico, baixo rendimento escolar, depressão, entre outros.

Em relação ao conhecimento dos docentes acerca do Transtorno de Déficit de Atenção e Hiperatividade, podemos verificar que as respostas são praticamente de senso comum, com pouca fundamentação do assunto, porém caracterizam o transtorno. Entre elas, a mais votada, é que a criança tem dificuldade em manter a atenção nas atividades e de relacionar-se com os colegas nas atividades de lazer. Outro ponto levantado foram os estímulos externos que atraem a atenção da criança, causando tal falta de atenção para as atividades, e nesse quesito a resposta de que os estímulos distraem acabam afetando a organização da sala e dos materiais dos alunos que apresentam TDAH. A dificuldade de esperar sua vez para falar e ser ouvido também aparece dentre as questões levantadas pelos professores, pois isso dificulta a organização da sala como um todo.

Pode-se perceber o que os professores têm conhecimento a respeito do transtorno e como lidar com as crianças portadoras do TDAH. As inquietações iniciais do trabalho aos poucos foram sendo esclarecidas, o que nos proporciona uma atenção na relação do trabalho docente e o transtorno. Um dos objetivos é proporcionar aos profissionais de educação um esclarecimento a respeito do Transtorno de Déficit de Atenção e Hiperatividade, de modo a usar uma linguagem clara e objetiva.

Dessa forma, podemos concluir que apesar dos docentes saberem a respeito do transtorno, ainda não tem total discernimento em diferenciar o transtorno de comportamentos excessivos dessas crianças, ou de hábitos como má educação ou de força de vontade ou preguiça como mesmo foi apontado na pesquisa.

Saber diferenciar os sintomas do TDAH é importante para a realização de um diagnóstico precoce e intervenções que sejam capazes de permitir a evolução e o desenvolvimento escolar e pessoal dessas crianças. Como pudemos notar, o diagnóstico precoce ocorre, geralmente, na escola com a percepção do professor, e se este tiver conhecimento, base teórica, fundamentação e ferramentas que levem a este diagnóstico, com certeza o rendimento acadêmico, do aluno e da sala de aula no geral, serão positivos.

Como foram dissertadas no artigo, as características do TDAH dificultam o desempenho normal da criança nos diversos ambientes, podendo repercutir no cotidiano delas. Identifica-se ainda, que nos comportamentos que mais prejudicam as crianças com o TDAH existem dúvidas com relação às atitudes, dos que são considerados comportamento ou meramente ações efêmeras, pois o brincar é fundamental para o desenvolvimento da criança, sendo considerada uma ação e não um comportamento, da mesma forma o falar alto e nervosismo, podem ser algo transitório. Tais ações devem ser consideradas a situação em que ocorrem as atitudes, a estrutura do ambiente escolar e a familiar, e a frequência que esses comportamentos costumam ocorrer.

A familiaridade dos profissionais com o TDAH pode ser observada em frases como: "Um transtorno neurobiológico que afeta o comportamento e a atenção"; "Transtorno neurológico, genético que pode se prolongar pela vida adulta"; "Minha 
filha e experiência com os estudantes no decorrer da minha vida profissional"; "Dificuldade de concentrar-se"; "Principalmente a dificuldade de concentração nas atividades"; "A criança não consegue se concentrar, se distrai facilmente"; "Infelizmente muito pouco, sei apenas que o indivíduo não consegue se concentrar e tem dificuldades de aprendizagem"; "A criança fica muito agitada, fica dispersa"; "Os comportamentos das crianças, eles são muito agitados, não gostam muito de barulho etc."; "Dificuldade de aprendizagem, assimilação, agitação em todos os momentos, impulsivo".

Para esses professores os problemas de escolarização são aspectos ainda relacionados ao relacionamento familiar que pode ser delicado, talvez até pelos sintomas característicos do transtorno sendo facilmente confundidos com outros distúrbios, problemas socioculturais, emocionais e familiares.

Em relação aos pares escolares, os professores puderam notar que o TDAH é mais rápido nas atividades e sem muita concentração, apresenta comportamentos diferenciados e atípicos (principalmente social, dificuldade em interagir entre eles), acaba sendo excluído pelos colegas devido a agitação e comportamento e agressividade, uma relação com conflituosa com dificuldades de relacionamento. Dificuldade de entrosamento e pouca participação nas atividades propostas.

Nas hipóteses levantadas sobre o papel do professor estão: minimizar os conflitos e auxiliar no desempenho acadêmico, aplicar aos alunos com TDAH atividades que despertem seus interesses, com conteúdo mais explícito e poucas comandas devido à pouca concentração, atividades mais dinâmicas sempre com intervenção. Buscar ajuda de profissionais, familiares e elaborar atividades coerentes para ajudar no desenvolvimento da criança. Saber a escolha das atividades adequadas, para um bom aprendizado e preparar plano de aula e atividades específicas, além de demonstrar interesse para que o aluno se sinta à vontade e igual aos outros e motiválo a todo momento, disponibilizando atividades que façam a criança interagir com o grupo.

Devido à grande circulação de informações nas redes sociais, grupos de atendimento, blogs e toda mídia digital, proporciona aos professores um leque cada vez maior com informados sobre o TDAH, e outros transtornos, as possíveis causas que podem prejudicar a aprendizagem e afetar o desenvolvimento da criança, direcionando-as para um profissional especializado diagnosticar precisamente.

Existe ainda a necessidade de pensar no docente como um formador de pessoas, que precisa ser formado também, proporcionando a qualidade de vida desses professores, valorizando-os cada dia mais, pois mesmo em condições não favoráveis fazem o melhor pelos seus alunos, procurando novos métodos e condições para o aperfeiçoamento pessoal.

Além das manifestações comportamentais causadas por questões que exigem um atendimento singular com psicólogos, fonoaudiólogos, psicoterapeutas, neurologistas e outros, devemos considerar questões sociais relativas à criança, família e fatores externos (drogas e medicamentos irregulares, automedicação). A diferenciação de tais características é essencial para não rotular imprecisamente. No rol das informações estando divulgadas como são, é preocupante que na lista dos 
professores ainda sejam apontadas possíveis causas de tais comportamentos a "má educação" e a "preguiça".

Nesses casos, a atenção do professor deve focar, pois o que pode ser julgado como má educação ou preguiça pode ser algo relacionado a um transtorno. Nos estudos de Bonet, Solano e Soriano (2008) foram identificados que o transtorno de déficit de atenção e hiperatividade pode se manifestar na idade escolar, sendo que nesse ambiente a criança precisa de mais autorregulação, cumprimento de normas, relacionamento com seus pares, e especialmente, ter foco e manter a atenção.

As dificuldades que o indivíduo portador do TDAH apresenta são diversas e perduram por toda vida e, uma mediação precoce poderia minimizar os efeitos de uma análise mal formulada. Neste rumo a escola deve desempenhar o papel de prevenir ações desenvolvendo programas de incentivo aos docentes a fim de conhecer e especializar no assunto, traçando estratégias em conjunto facilitando a vida dos portadores de TDAH.

$\mathrm{O}$ autor Celso Antunes (2008), disserta que o apoio do professor unindo a tolerância à exigência é sempre importante para a criança na fase de desenvolvimento, pois é ele que vai demonstrar através do afeto que o aluno é capaz de superar as dificuldades, exigindo a superação com amor e cautela.

\section{Referências}

ANTUNES, Celso. Inclusão: o nascer de uma pedagogia. São Paulo: Ciranda Cultural, 2008. - (Um olhar para a educação).

ASSEMBLÉIA GERAL DAS NAÇÕES UNIDAS. Declaração Universal dos Direitos Humanos. Resolução 217 A (III), Io dez. 1948. Disponível em: < http://portal.mj.gov.br/sedh/ct/legis_intern/ddh_bib_inter_universal.htm> Acesso em: 02 fev. 2010.

BARKLEY, Russell A. \& colaboradores. Transtorno de Déficit de Atenção/Hiperatividade: manual para diagnóstico e tratamento. 3a Ed. - Porto Alegre: Artmed, 2008.

BONET, Trinidad; SORIANO, Yolanda; SOLANO, Cristina. Aprendendo com crianças hiperativas: um desafio educativo. São Paulo: Cengage Learning, 2008.

BRASIL. Estatuto da Criança e do Adolescente no Brasil - ECA. Lei n. 8.069, de I3 de julho de $1990 . \quad$ Disponível em:

http://www.planalto.gov.br/ccivil_03/leis/L8069 Compilado.htm> Acesso em: 14 out. 2013.

BRASIL. Declaração de Salamanca e linha de ação sobre necessidades educativas especiais. Brasília: UNESCO, 1994.

BRASIL. Lei de Diretrizes e Bases da Educação Nacional. Lei 9.394/96. Disponível em 〈https://www.planalto.gov.br/ccivil_03/Leis/L9394.htm> Acesso em: o8 dez. 2016. 
BRASIL. UNICEF. Declaração Mundial de Educação para Todos e plano de ação para satisfazer as necessidades básicas de aprendizagem. Brasília: Fundos das Nações Unidas para a Infância, 1990.

BRASIL. Secretaria de Educação Fundamental. Parâmetros curriculares nacionais: Adaptações Curriculares / Secretaria de Educação Fundamental. Secretaria de Educação Especial. - Brasília: MEC /SEF/SEESP, i998. p. 62. Disponível em: < http://www.conteudoescola.com.br/pcn-esp.pdf> Acesso em: or nov. 2016.

BROWN, T. E. Transtorno de Déficit e Atenção: a mente desfocada em crianças e adultos. Porto Alegre: Artmed, 2007.

CERVO, A. BERVIAN, P. A.; \& DA SILVA, R. Metodologia Científica. - 6a Ed. - São Paulo: Pearson Prentice Hall, 2007.

DUEK, V. P. \& NAUJORKS, M. I. Docência e inclusão: reflexões sobre a experiência de ser professor no contexto da escola inclusiva. Dissertação de Mestrado. Universidade Federal de Santa Maria - UFSM. 2016.

FUNDAÇÃO VICTOR CIVITA. Inclusão: como ensinar os conteúdos do currículo para alunos com deficiência. Revista Nova Escola - Edição Especial, São Paulo: Abril S.A., $\mathrm{n}^{\circ}$ 24, p. 4-66, jul. 2009.

LUCK, Heloísa. Gestão educacional: uma questão paradigmática. 3a Ed. - Petrópolis, RJ: Vozes, 2007. Série Cadernos de Gestão.

MARCONI, M. A. \& LAKATOS, E. M. Técnicas de Pesquisa: planejamento e execução de pesquisa, amostragens e técnicas de pesquisas, elaboração, análise e interpretação de dados. 5. Ed., São Paulo: Atlas, 2002.

MATTOS, P. No mundo da lua: perguntas e respostas sobre transtorno do déficit de atenção com hiperatividade em crianças, adolescentes e adultos. São Paulo: Lemos Editorial, 2003.

DSM-V, Manual diagnóstico e estatístico de transtornos mentais. American Psychiatric Association, tradução. Maria Inês Corrêa Nascimento, et al. Porto Alegre: Artmed, 948 p. 2014.

ORGANIZAÇÃO MUNDIAL DA SAÚDE / ORGANIZAÇÃO PANAMERICANA DA SAÚDE. CID Io - Classificação estatística internacional de doenças e problemas relacionados à saúde. ıoa revisão. São Paulo: EDUSP, 2000. Disponível em: < http://www.datasus.gov.br/cidio/v20o8/webhelp/cidıo.htm> Acesso em: 20 set. 2016. 
REGO, T. C. Vygotsky: Uma perspectiva histórico-cultural da educação. Petrópolis, RJ: Vozes, 2002.

SANTOS, J. B. A "dialética da exclusão/inclusão" na história da educação de 'alunos com deficiência'. Revista da FAEEBA/Universidade do Estado da Bahia, Faculdade de Educação do Estado da Bahia - Educação e Contemporaneidade. Salvador: v.II, n. I7, p. $27-44$, jan/jun., 2002.

TARDIF, M. Saberes docentes e formação profissional. Petrópolis: Vozes, 2002.

VICARI, M. I. Melhorando a atenção e controlando a agitação. São Paulo: Thot Cognição e Linguagem, 2006. 